\title{
Childhood Obesity: A Perspective on Compromises in Immunity, Cardiovascular Health, Metabolic Health of Children and Preventive Strategies
}

ISSN: 2578-0263

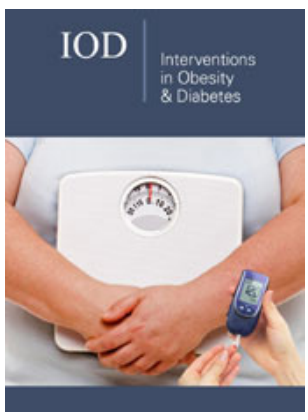

*Corresponding author: Rajasekhar Kali Venkata, Wellness and Sports Sciences Researcher, Director of Physical Education and Sports, University of Hyderabad, India

Submission: 望-1) January 11, 2021

Published: 疅 February 22, 2021

Volume 5 - Issue 1

How to cite this article: Rajasekhar Kali Venkata, Srinivasan MV. Childhood Obesity: A Perspective on Compromises in Immunity, Cardiovascular Health, Metabolic Health of Children and Preventive Strategies. Interventions Obes Diabetes 5(1). IOD.000601. 2021. DOI: 10.31031/IOD.2021.05.000601

Copyright@ Rajasekhar Kali Venkata. This article is distributed under the terms of the Creative Commons Attribution 4.0 International License, which permits unrestricted use and redistribution provided that the original author and source are credited.

\author{
Rajasekhar Kali Venkata ${ }^{1 *}$ and Srinivasan MV² \\ ${ }^{1}$ Director of Physical Education and Sports Sciences, University of Hyderabad, India \\ ${ }^{2}$ Associate Professor in Physical Education, Sri Krishnadevaraya University, India
}

\section{Abstract}

Presence of excessive body fat percentage in the body than the normal proportion may be considered as obesity. The measure of Body Mass Index (BMI) is considered still as the population parameter to specify the overweight and obesity. The advent of several advanced scientific methods like Bio-impedance electrical technology etc. are able to measure the body composition more precisely and now the understanding on the obesity is more specific. Childhood obesity measure is not universal as there are several exogenous and endogenous causes for childhood obesity. The possibility of obese children grow into obese adults is more and may lead for health disaster for countries high with childhood obesity. The spread of childhood obesity seems very severe, alarming and epidemic like, the countries like Canada, USA, China, India etc. are facing this problem more severely. Increasing physical inactivity, aberrant food habits like eating junk and processed foods are the biggest factors that are causing the childhood obesity across the globe. Epigenetic studies are also indicating that the childhood obesity is mostly due to the exogenous factors of lifestyle than endogenous factors. Effective strategies to counter the childhood obesity need to be implemented with immediate effect to mitigate the economic cost and also to alleviate the misery from the premature deaths of young people. Encouragement to recognize aesthetics in daily life among children is an effective strategy to offset the childhood obesity.

Keywords: Body fat percentage; Body mass index; Childhood obesity; Physical inactivity; Epigenetic studies

\section{Introduction}

The present scenario in the entire globe with respect to the Obesity seems increasingly threatening. The problem of Obesity has almost reached to the extent of pandemic and is causing severe health consequences. The obesity per se may not be a disease, but the condition of obesity among individuals could cause for several problems including immune suppression, cardiovascular health issues, metabolic health issues etc [1]. The World Health Organization has identified over weight and the obesity of individuals basing on the Body Mass Index indicator. The WHO has identified that the individuals as overweight who are with $25 \mathrm{BMI}$ to below $30 \mathrm{BMI}$ and those with above $30 \mathrm{BMI}$ as obese individuals. However, the credibility of the measure of BMI seems questionable as the BMI do not consider the fat portion of the individual, but simply takes into cognizance only the body mass. Several studies clearly indicated that the sportspersons, body builders, high intensity sportspersons etc. may show higher BMI though their fat percentage is low because of the higher lean body mass like higher muscle and bone density. But, still the measure of BMI is extensively used as a population measure to understand the obesity [2]. Using the measure of BMI for individual obesity evaluation could be unscientific. The emergence of the other scientific methods like Bio impedance electrical analysis technology (BIA), Computer tomography (CT scan), Magnetic Resonance Imaging (MRI) etc., made the identification of body composition very specific and near accurate, through which the fat percentage of the individuals may be assessed more precisely. The precise operational definition for Obesity is still to come, but the scientific studies accepted that the obesity may be recognized as presence of excessive body fat in the body. But the range of body fat percentage and the scales to identify the Obesity basing on the body fat percentage seems more of specific population wise than a generic and worldwide common standard [3]. The same is also true and valid for the childhood obesity, and there is not universally acceptable cut off point for body fat percentage or for BMI to measure and identify the childhood obesity. There were several regional scientific studies, mostly conducted 
with an initiative from the regional governments, identified their population specific cut off points for body fat percentages or using the BMI to identify scales for Obesity measurement among children which are specifically useful for their respective regions or countries. Williams et al. [4] conducted a study on 3,320 children in the age group of five to eighteen years and identified that the body fat percentage in excess of 25 as obese for male and 30 percent for female children but may not be extended to the children in general. The problem of childhood obesity is growing in an alarming ratio across the globe, without any delimitations [5]. Though initially, the childhood obesity was a big concern among the high-income countries like Canada [6], USA etc. now the childhood obesity is raising pandemic alarms even in the low income and undeveloped countries. The urban areas of the world in general without any exception are experiencing this childhood obesity in extremely high proportions and the impact due to this may be a catastrophe $[7,8]$. The speedier economic growth in china caused for childhood obesity across many Chinese cities [9]. In the European Union, one among every three children is either overweight or obese [10]. The prevalence of overweight and obesity among the children in several European cities is highly worrying [11]. The discussion on the etiology on obesity and preventive strategies are the main concern in this article and hence the epidemiological data like definition, measurement and prevalence part of obesity is not fully elucidated.

\section{Health Risks of Obesity}

There are many health consequences of childhood obesity. Some studies are indicating that the children who are overweight and obese may eventually grow up into overweight or obese adults. The adult obesity could cause for several health risks like, metabolic syndrome, which may cause for several clusters of pathophysiological conditions that may cause cardiovascular problems [12], Diabetes mellitus, Arthritis, Several types of cancers, organ dysfunction especially kidney dysfunction [13] etc. Previously, these health risks were seen mainly among the adults, but now cardiovascular events promoting or causing cardiovascular disorders [4], metabolic disorders are not uncommon even among the obese children who are below fifteen years of age and this is a worrying concern for the governments. The growing childhood obesity could cause severe strain on the health status of the globe and may cause immense misery due to increased premature deaths in young people. Hence, it is an immediate necessity, to identify the childhood obesity issues and control them with immediate effect. More recently, the obesity paradox has been discussed upon, which indicate that the obese individuals respond better under critical care than the non-obese individuals, which needs to be examined in wider scientific settings. This hypothetical obesity paradox seems to be based on the inflammatory effects of the adipose tissue which might cause for inducing the more protective pro inflammatory condition [14]. However, the same need to be understood more extensively. The present scientific evidence are favoring the negative effects of the excessive adipose tissue in terms of enhancing the pro inflammatory cascades [15], which is according to the obesity paradox proponents, a self-defense mechanism of human adaptation.

Obesity, through the excessive adipose tissue, especially the white adipose tissue, causes for low grade chronic inflammation, and consequently the presence of several pro inflammatory cytokines increases [16]. Though inflammation is a necessary physiological phenomenon that restores homeostasis in the infected or injured tissue, but the uncontrolled and chronic inflammation could induce disease condition, due to the presence of inflammatory cytokines like Interleukn-6 (IL-6), Tumor Necrosis Factor $\alpha$ (TNF $\alpha$ ) etc. The increased presence of the IL- 6 could induce the liver to produce $C$ reactive protein, which may cause for several cardiovascular events like intimal hyperplasia and disintegration, atherosclerosis. This inflammatory cytokine also can induce insulin resistance leading to diabetes conditions. Adipose tissue produces both anti and pro inflammatory cytokines, which are responsible for several physiological conditions. The problem of inflammation in adipose tissue seems to be due to the over expression of certain cytokines produced in the adipose tissue [17]. They not only cause for the significant levels of inflammation but also cause for the suppression of the pro inflammatory cytokines like adiponectin etc. The reduced or under expressed adiponectin could induce coronary artery calcification, impaired glucose tolerance and several other metabolic abnormalities, promoting the congenial physiology for development of Diabetes mellitus and/or atherosclerosis of arteries. A vicious cycle may be seen as a consequence of the chronic low-grade inflammation in adipose tissue. The over expression of inflammatory cytokines like IL-6, IL- 1 and TNF $\alpha$ could cause for the prooxidative state in the tissues [18], initiating Reactive Oxygen Species (ROS). These in turn promote the expression of the pro inflammatory cytokines of adipose tissues [19]. This unrestricted and chronic inflammation and oxidative stress [20] could further induce conditions that would favor for the infiltration of macrophages leading to enhanced phagocytic activity and this would enhance the endothelial cell dysfunction and vascular inflammation, which may be valid for the conditions of pediatric obesity [21]. Excessive and chronic inflammation could also promote the immune suppression through the hyper expression of immune suppression cells like Myeloid derived suppressor cells (MDSCs). There are evidence that the regulatory $\mathrm{T}$ cells or Tregs, which are subsets of $\mathrm{CD} 4^{+} \mathrm{T}$ cells could be suppressed and hence leading to lack of control in auto immune cells activity at various tissues [22,23]. These kinds of negative events due to the chronic inflammation and oxidation, several other organs like kidneys and liver may get tissue and organ damages [24]. Obesity may indirectly could cause for kidney and liver dysfunction and damage [24-26]. Unlimited number of negative events can be attributed to the presence of obesity in individuals and also in children that may lead for several health consequences including the premature death.

Another viable and important issue to be noted with respect to the risks of obesity is malnutrition due to mal-absorption [27]. Excessive fat in adipose tissues could cause mal-absorption, 
transportation and metabolism of micronutrients, exposing individuals to several health risks [28-30]. The possibility of lower serum Vitamin D, magnesium, potassium, folate, Selenium etc. among the obese individuals, possibly due to the mal-absorption [31-33]. Selenium deficiency may be related to enhanced pathophysiology for malignancies and cardiomyopathy [34], as selenium acts as a potent antioxidant through the glutathione signaling. Studies also indicated that some of the categories of phytochemicals, especially the carotenoids are fat soluble and hence, the circulating plasma carotenoids could be dangerously low among obese individuals due to the storage of these carotenoids in adipose tissue as they are lipid soluble [35]. As one may lead to the other, the deficiency of Vitamin D due to mal-absorption among the obese individuals could cause for the mal-absorption of magnesium deficiency [36,37]. Deficiency of magnesium could cause for nervous system problems, osteoporosis, pulmonary function issues, cardiovascular issues like high blood pressure and several [38,39]. Nutritional deficiencies among the obese individuals may be not only due to the mal-absorption but may also be due to oxidative stress, but appropriate nutritional strategies could control the negative events of the childhood obesity to some extent [23]. Emotional and psychological problems of obesity among children need to be emphasized properly, as they may lead for severe psychological pressure on them and could cause for the further health risks [40]. The emotional issues of childhood obesity are self-esteem, depression symptoms, being ridiculed for being fatty etc. Constant psychological stress could also induce stress element among the children and the stress physiology indicates that the continuous psychological stress could induce for excessive flow of inflammatory hormones like Cortisol and Catecholamines [41]. Excessive flow of cortisol could cause for cortical insufficiency and excessive flow of catecholamines may cause for aberrations in sympathetic nervous system and could lead to cardiac arrhythmias, increased blood pressure etc. [42].

\section{What Causes of Childhood Obesity}

There are several causes which may induce for the excess fat accumulation among children and eventually to make them overweight and obese. Nutritional flaws, physical inactivity, Stress in daily life, genetic problems including the prenatal events, hormonal disorders, psychological factors like lack of self-esteem, motivation, lack of parental guidance, socio economic factors like higher income levels, sociological issues like lack of appreciation for beauty among the general population are some of the very important causes for the childhood obesity [43]. The main causes for childhood obesity seem the nutritional and inactivity.

\section{Excessive intake than expenditure}

Excessive food intake in terms of calories than the spent calories would cause for the accumulation of the fat as the excessive carbohydrate and proteins also would get converted into fatty acids to be stored in adipose or fat tissue [44]. So, the macro elements of nutrition (Carbs, proteins and fats) need to be consumed in a very precise manner that would suit for the daily requirement basing on the type of activity performed during the day. The nutritional flaw may be not only due to the excessive intake of calories but also due to obesity itself, as there could be malnutrition due to malabsorption, transportation and metabolism of micronutrients among obese individuals [45]. Also, children may tend to develop fascination towards particular type of food and may crave to eat more of the same like candies, pastries, junk foods like pizzas and burgers etc. Mostly these kinds of foods have more processed carbs and sugars than other important nutrients. Some of the foods, especially those food sources which contain micronutrients like vitamins and minerals belong to green leafy vegetables, fruits and colored food substances, that may also act on the satiety center as they contain not only the micronutrients but also great amount of fiber. Studies are indicating that the children tend to tilt towards the junk foods than the foods that contain the micronutrients and fiber due to the taste factor $[46,47]$. Parental ignorance on the nutrition may be another factor that may contribute for childhood obesity. Several children may not like the consumption of the fermented foods like curd, yoghurt, probiotic foods are essential to protect and promote the gut micro biota, which may influence the Central nervous system and even the Hypothalamus-Pituitary-Adrenal axes, which could control the endocrinal health.

\section{Physically active lifestyle}

Regular exercises is an important lifestyle factor that might control the obesity among individuals, through burning of calories [48]. However, it is pertinent to note that the nutritional balance is very essential even if an individual is active and doing regular exercises. This lifestyle factor may be a very valuable correction factor for obesity among children and also among adults as well.

\section{Stress in daily life}

Stress may exist in any form in the children due to the education pressure from parents, peers and society and certainly influences the psychological status and consequent behaviors of the children [49]. Lack of enough time to spare for physical activity after meeting the required education demands that are growing in the modern education scenario as the expectations from the outside world is enormous. Though this aspect was truer and more relevant for the adolescent students previously, now the things are truer even to the young children of five to fifteen years age. Compatible family environment may also influence the attitude of the children towards nutrition and physical activity.

\section{Prenatal events}

Intrauterine life of the child is so influential in terms of the future childhood obesity including maternal stress during pregnancy [50]. The maternal food habits and the gestational weight gain are two important issues in this regard [51]. Consumption of junk foods, high calorie diet, and micronutrient deficient nutrition by mother could influence the intrauterine environment of the child that may cause for the childhood obesity [52]. Some studies indicated that the children obesity and metabolic syndrome may sometimes originate at the intrauterine life of the child and this may even extend into the adult obesity. 


\section{Genetic orientation}

Studies on genetic predisposition with respect to Obesity, Diabetes etc. are happening, but with minimum success, as these are multifactorial or complex diseases which may be the outcome of the interaction of several physiological conditions that may require the involvement of pools of genes in interaction [53]. The genotype studies for Obesity are not so successful, except in few types of populations. The loci of the gene may be in tandem to the insulin gene, but the allele variations are further studied in this regard. A study on Caucasian neonates indicated that a polymorphism of 1 VNTR paternal allele could predispose the fat accumulation in the early childhood. There were some studies, which indicated that the single gene mutation which may be termed as monogenic may also cause obesity and it is true in case of leptin gene [54].

\section{Hormonal disorders}

In general, most of the childhood obesity may be considered as exogenous as physical inactivity, nutritional factors etc. But there are some endogenous factors that may also contribute for the childhood obesity. Endocrinal dysfunction due to several epigenetic events during the childhood might contribute for this [55], though the origins epigenetic factors could be exogenous like nutritional problems, exercise issues, stress related issues, therapeutics etc [56]. These epigenetic events could cause for methylation of the genetic material that might bring changes in the endocrinal health and consequent hormonal dysfunction. Hypothyroidism may be considered as one of the factors that might contribute for the fat accumulation among children.

\section{Psychological factors like self-esteem, motivation etc.}

Umpteen reasons could be ascribed for the psychological status of a child. Due to the interaction of several causative factors a child may develop certain psychological traits which may reflect in low self-esteem [57], low motivation levels etc. These traits could result in low traverse among the children that might cause for disinterest and disorientation towards good lifestyle aspects that may prevent obesity. Obese children may be exposed to certain kinds of ridicules due to overweight and the fatty appearance from the peers and this in turn may make them more dormant in their nature to become increasingly obese $[58,59]$. Childhood obesity may create a vicious cycle through which the child become more obese. But the children with higher self-esteem and motivation may fight against the odd situation and may try to control their obesity [60].

\section{Lack of appreciation for beauty}

This is now considered as one of the very important psychosociological influencing factors for adult obesity control. The studies are indicating that the people in general are less and less interested in terms of showing interest in aesthetics and beautiful bodies. The aesthetically carved statues of Greece and Ancient Indian temples were probably to bring out the aesthetic sense among the general population and to make them strive to achieve such beautiful bodies through proper exercise, nutrition and other lifestyle factors. As the beautiful and aesthetic bodies represent the fitness levels of the individuals and hence aesthetic body may be considered as synonymous to the healthy body. The decreasing trend in the aspects of aesthetics and beauty in the perspectives of the general population could cause for overweight and fatty bodies. Despite the difficulties in sexual life and problems of conception, the majority of men and women are disoriented to pick up aesthetics in their life. The same is also true with the children of the modern era. Children are not aware about aesthetics, and there may be several reasons for this, including the parental presence.

\section{Socio economic status of the children}

Children tend to be more affluent in terms of food habits, when the disposable income is high. There were trends observed in high income countries and especially in urban areas [61] where the available income is high for the parents, the propensity of the children seems more towards the high calorie junk foods and might be a potential reason for the childhood obesity. The urban areas being more easily accessible to junk foods, when compared to the rural areas [62], even the low in come country children who are in urban set ups showed much higher obesity.

\section{Parental influence}

Many a time, the behavior of parents with the child, and the motivation levels of parents towards the lifestyle issues might contribute much in terms of childhood obesity. Parental behavior patterns towards the children and the attentional attitude of parents towards the children is necessary to control the obesity levels of the children. Generally, children tend to follow the parents, during the early childhood in terms of their physical activity, maintaining body aesthetics etc. This is truer when comes to the pre-adolescent children. Stressed out parents might not be able to monitor the child's preferences in terms of diet, physical activity and other lifestyle aspects [63]. Strategies for tackling the childhood obesity: Several countries have started sincere and diligent efforts to tackle this childhood obesity problem. The phenomenon of childhood obesity seems a very threatening health issue for the whole world. An urgent need is there to tackle this problem to save millions of people dying prematurely and also to reduce the medication and treatment expenditure. Physical activity needs to be improved among the children in general, with specific encouragement towards participation of group physical activities, which may take care of physical, psychological and sociological wellness of the children simultaneously [64]. Creation of infrastructure in schools and in various public places seems a very crucial element in promoting physical activity among children. More importantly, the children need to be made to recognize the importance of the fitness in management of health. It would be ideal to implement educational strategies like inclusion of health fitness, health nutrition, stress management and other relevant issues as compulsory study subjects [65]. The children who are not school going need to be provided with an opportunity to have the facilities and media presentations to make them aware. Children need to be encouraged to know and get familiarize about the beauty and aesthetics to make them tilted towards the physical activity and 
controlled lifestyle. Making children getting equipped to an attitude by instilling higher motivation that makes them more adhering to better lifestyle [66] makes them to pass on the same into adult life, which would bring higher benefits [67]. Nutritional strategies to target the school going children may be easier, hence more impetus need to be put on the children who do not attend schools. Parental guidance and parental involvement are another important strategy that would bring great results in controlling the childhood obesity. There are several recommendations with respect to the possible strategies to tackle childhood obesity by several researchers, mainly basing on the geographical, socio-economic factors of children population targeted [68].

\section{Conclusion}

Lack of enough physical activity, lack of scientific nutritional practices, lack of proper parental guidance, lack of knowledge on the scientific aspects of fitness, immunity and health, lack of general disorientation towards the beauty and aesthetics, trend in decreased time availability to the children, decreased self-esteem and motivation in terms of physical exercise and many other factors are making the problem of childhood obesity more aggravated. Childhood obesity in the world is increasing in unfathomable proportions without any limitation to the economic status of countries. Obese children may prosper into obese adult individuals and could cause severe strain on the global economy. Decreased health status and premature deaths of young individuals could be disastrous and a great misery. Childhood obesity is slowly becoming into a pandemic proportion and could be a catastrophe, hence need to be tackled immediately with specific and achievable strategies that may reduce the childhood obesity considerably. There should be sincere and scientific efforts to understand the reasons of childhood obesity and implement the methods to offset the problem with concerted efforts.

\section{References}

1. Paes ST, Marins JC, Andreazzi AE (2015) Metabolic effects of exercise on childhood obesity: A current view. Rev Paul Pediatr 33(1): 122-129.

2. Nurwanti E, Hadi H, Chang JS, Chao JCJ, Paramashanti BA, et al. (2019) Rural-urban differences in dietary behavior and obesity: Results of the riskesdas study in 10-18-year-old Indonesian children and adolescents. Nutrients 11(11): 2813.

3. Martin CL, Siega Riz AM, Stores Alvarez D, Robinson WR, Daniels JL, et al. (2016) Maternal dietary patterns during pregnancy are associated with child growth in the first 3 years of life. J Nutr 146(11): 2281-2288.

4. Williams DP, Going SB, Lohman TG, Harsha DW, Srinivasan SR, et al. (1992) Body fatness and risk for elevated blood pressure, total cholesterol, and serum lipoprotein ratios in children and adolescents. Am J Public Health 82(3): 358-363.

5. Vinceti M, Filippini T, Del Giovane C, Dennert G, Zwahlen M, et al. (2018) Selenium for preventing cancer. Cochrane Database Syst Rev 1(1): CD005195.

6. Rankin J, Matthews L, Cobley S, Han A, Sanders R, et al. (2016) Psychological consequences of childhood obesity: Psychiatric comorbidity and prevention. Adolesc Health Med Ther 7: 125-146.

7. Congdon P (2019) Obesity and urban environments. Int J Environ Res Public Health 16(3): 464.
8. Umano GR, Pistone C, Tondina E, Moiraghi A, Lauretta D, et al. (2019) Pediatric obesity and the immune system. Front Pediatr 7: 487.

9. Wang Y, Lim H (2012) The global childhood obesity epidemic and the association between socio-economic status and childhood obesity. Int Rev Psychiatry 24(3): 176-188.

10. Miguel GM, Oliveira A, Redondo CI, Bueno CA, Carrascosa DPP, et al. (2019) Prevalence of overweight and obesity among european preschool children: A systematic review and meta-regression by food group consumption. Nutrients 11(7): 1698.

11. Bemelmans WJE, Wijnhoven TMA, Verschuuren M, Breda J (2014) Overview of 71 European community-based initiatives against childhood obesity starting between 2005 and 2011: General characteristics and reported effects. BMC Public Health 14: 758.

12. Bridger T (2009) Childhood obesity and cardiovascular disease. Paediatr Child Health 14(3): 177-182.

13. Koch VH (2019) The effects of obesity on kidney function: A challenge for nephrologists. J Bras Nefrol 41(2): 162-165.

14. Carbone S, Canada JM, Billingsley HE, Siddiqui MS, Elagizi A, et al. (2019) Obesity paradox in cardiovascular disease: where do we stand? Vasc Health Risk Manag 15: 89-100.

15. Banack HR, Kaufman JS (2014) The obesity paradox: Understanding the effect of obesity on mortality among individuals with cardiovascular disease. Preventive Medicine 62: 96-102.

16. Castro AM, Macedo de la Concha LE, Pantoja Meléndez CA (2017) Lowgrade inflammation and its relation to obesity and chronic degenerative diseases. Revista Médica del Hospital General de México 80(2): 101-105.

17. Ellulu MS, Patimah I, Khazaai H, Rahmat A, Abed Y (2017) Obesity and inflammation: The linking mechanism and the complications. Arch Med Sci 13(4): 851-863.

18. Kilic E, Özer ÖF, Toprak EA, Erman H, Torun E, et al. (2016) Oxidative stress status in childhood obesity: A potential risk predictor. Med Sci Monit 22: 3673-3679.

19. Lechuga Sancho AM, Andujar DG, Ocaña PR, Visiedo FM, Benito AS, et al. (2018) Obesity induced alterations in redox homeostasis and oxidative stress are present from an early age. PLOS ONE 13(1): e0191547.

20. Peterson CA, Belenchia AM (2014) Vitamin D deficiency \& childhood obesity: A tale of two epidemics. Mo Med 111(1): 49-53.

21. Tate EB, Wood W, Liao Y, Dunton GF (2015) Do stressed mothers have heavier children? A meta-analysis on the relationship between maternal stress and child body mass index. Obes Rev 16(5): 351-361.

22. Carolan E, Hogan AE, Corrigan M, Gaotswe G, Connell JO, et al. (2014) The impact of childhood obesity on inflammation, innate immune cell frequency, and metabolic MicroRNA expression. The Journal of Clinical Endocrinology \& Metabolism 99(3): E474-E478.

23. Moro García MA, Mayo JC, Sainz RM, Arias RA (2018) Influence of inflammation in the process of $\mathrm{T}$ lymphocyte differentiation: Proliferative, metabolic, and oxidative changes. Front Immunol 9: 339.

24. Ding W, Cheung WW, Mak RH (2015) Impact of obesity on kidney function and blood pressure in children. World J Nephrol 4(2): 223-229.

25. Jadresic L, Silverwood RJ, Kinra S, Nitsch D (2019) Can childhood obesity influence later chronic kidney disease? Pediatr Nephrol 34(12): 24572477.

26. Scott KA, Melhorn SJ, Sakai RR (2012) Effects of chronic social stress on obesity. Curr Obes Rep 1(1): 16-25.

27. García OP, Ronquillo D, del Carmen Caamaño M, Martínez G, Camacho M, et al. (2013) Zinc, iron and vitamins A, C and E are associated with obesity, inflammation, lipid profile and insulin resistance in Mexican school-aged children. Nutrients 5(12): 5012-5030. 
28. Camilleri M, Malhi H, Acosta A (2017) Gastrointestinal complications of obesity. Gastroenterology 152(7): 1656-1670.

29. Neovius MG, Linné YM, Barkeling BS, Rossner SO (2004) Sensitivity and specificity of classification systems for fatness in adolescents. Am J Clin Nutr 80(3): 597-603.

30. Mocanu V (2013) Prevalence of overweight and obesity in urban elementary school children in Northeastern Romania: Its relationship with socioeconomic status and associated dietary and lifestyle factors. Biomed Res Int 2013: 537451.

31. García OP, Long KZ, Rosado JL (2009) Impact of micronutrient deficiencies on obesity. Nutrition Reviews 67(10): 559-572.

32. Lo Menzo E, Cappellani A, Zanghì A, Di Vita M, Berretta M, et al. (2014) Nutritional implications of obesity: Before and after bariatric surgery. Bariatr Surg Pract Patient Care 9(1): 9-17.

33. Pervanidou P, Charmandari E, Chrousos GP (2013) Endocrine aspects of childhood obesity. Curr Pediatr Rep 1: 109-117.

34. Via M (2012) The malnutrition of obesity: Micronutrient deficiencies that promote diabetes. ISRN Endocrinol 2012: 103472.

35. Lee H, Lee IS, Choue R (2013) Obesity, inflammation and diet. Pediatr Gastroenterol Hepatol Nutr 16(3): 143-152.

36. Zakharova I, Klimov L, Kuryaninova V, Nikitina I, Malyavskaya S, et al. (2019) Vitamin D insufficiency in overweight and obese children and adolescents. Front Endocrinol 10: 103.

37. McKay J, Ho S, Jane M, Pal S (2020) Overweight \& obese Australian adults and micronutrient deficiency. BMC Nutr 6: 12.

38. Zaakouk AM, Hassan MA, Tolba OA (2016) Serum magnesium status among obese children and adolescents. Egyptian Pediatric Association Gazette 64(1): 32-37.

39. Sidhu S, Parikh T, Burman KD (2000) Endocrine changes in obesity. In Feingold KR, Anawalt B, Boyce A (Eds.), South Dartmouth (MA), USA.

40. Schneiderman N, Ironson G, Siegel SD (2005) Stress and health: psychological, behavioral, and biological determinants. Annu Rev Clin Psychol 1: 607-628.

41. Kim JT, Lee HK (2017) Childhood obesity and endocrine disrupting chemicals. Ann Pediatr Endocrinol Metab 22(4): 219-225.

42. Thea M, Emilio J (2015) Childhood obesity: Immune response and nutritional approaches. Frontiers in immunology 6: 76.

43. Russell Mayhew S, McVey G, Bardick A, Ireland A (2012) Mental health, wellness, and childhood overweight/obesity. J Obes 2012: 281801.

44. Salvy SJ, Bowker JC (2014) Peers and obesity during childhood and adolescence: A review of the empirical research on peers, eating, and physical activity. J Obes Weight Loss Ther 4(1): 207.

45. Kim J, Lim H (2019) Nutritional management in childhood obesity. Journal of Obesity \& Metabolic Syndrome 28(4): 225-235.

46. Harris G (2008) Development of taste and food preferences in children. Curr Opin Clin Nutr Metab Care 11(3): 315-319.

47. Rao DP, Kropac E, Do MT, Roberts KC, Jayaraman GC (2016) Childhood overweight and obesity trends in Canada. Health Promot Chronic Dis Prev Can 36(9): 194-198.

48. Bülbül S (2020) Exercise in the treatment of childhood obesity. Turk Pediatri Ars 55(1): 2-10.
49. Sartorius K, Sartorius B, Madiba TE, Stefan C (2018) Does highcarbohydrate intake lead to increased risk of obesity? A systematic review and meta-analysis. BMJ Open 8(2): e018449.

50. Swaminathan R (2003) Magnesium metabolism and its disorders. Clin Biochem Rev 24(2): 47-66.

51. Leddy MA, Power ML, Schulkin J (2008) The impact of maternal obesity on maternal and fetal health. Rev Obstet Gynecol 1(4): 170-178.

52. Mariotti A (2015) The effects of chronic stress on health: New insights into the molecular mechanisms of brain-body communication. Future Sci OA 1(3): FSO23.

53. Mărginean CO, Mărginean C, Meliţ LE (2018) New insights regarding genetic aspects of childhood obesity: A minireview. Front Pediatr 6: 271.

54. Zhao J, Struan FA (2011) Genetics of childhood obesity. Journal of Obesity 2011: 845148.

55. Liu SC (2016) Pediatric obesity-related renal disease. Kidneycentric.

56. Parks EP, Kumanyika S, Moore RH, Stettler N, Wrotniak BH, et al. (2012) Influence of stress in parents on child obesity and related behaviors. Pediatrics 130(5): e1096-e1104.

57. Danielsen YS, Stormark KM, Nordhus IH, Mæhle M, Ekornås B, et al. (2012) Factors associated with low self-esteem in children with overweight. Obes Facts 5(5): 722-733.

58. Pirgon Ö, Aslan N (2015) The role of urbanization in childhood obesity. J Clin Res Pediatr Endocrinol 7(3): 163-167.

59. Sahoo K, Sahoo B, Choudhury AK, Sofi NY, Kumar R, et al. (2015) Childhood obesity: causes and consequences. J Family Med Prim Care 4(2): 187-192.

60. Borrello M, Pietrabissa G, Ceccarini M, Manzoni GM, Castelnuovo G (2015) Motivational interviewing in childhood obesity treatment. Front Psychol 6: 1732.

61. Franch PC, García LB, Jordá RS, Villaescusa CDC, Maldonado JM, et al. (2010) Is obesity associated with oxidative stress in children? Int J Pediatr Obes 5(1): 56-63.

62. Migliaccio S, Di Nisio A, Mele C, Scappaticcio L, Savastano S, et al. (2019) Obesity and hypovitaminosis D: causality or casualty? Int J Obes 9(1): 20-31.

63. Leocádio PCL, Oriá RB, Lopez MEC, Jacqueline IAL (2020) Obesity: More than an inflammatory, an infectious disease? Front Immunol 10: 3092.

64. Nuttall FQ (2015) Obesity, BMI, and health: A critical review. Nutrition Today 50(3): 117-128.

65. Rodríguez Ventura AL, Pelaez Ballestas I, Sámano Sámano R, Jimenez Gutierrez C, Aguilar Salinas C (2014) Barriers to lose weight from the perspective of children with overweight/obesity and their parents: A sociocultural approach. J Obes.

66. Rebello CJ, O Neil CE, Greenway FL (2016) Dietary fiber and satiety: The effects of oats on satiety. Nutr Rev 74(2): 131-147.

67. Mc Whorter JW, Wallmann HW, Albert PT (2003) The Obese child: Motivation as a tool for exercise. Journal of Paediatric Health Care 17(1): P11-P17.

68. Dong Y, Catherine JMS, Ma Y, Dong B, Zou Z, et al. (2019) Economic development and the nutritional status of Chinese school aged children and adolescents from 1995 to 2014: An analysis of five successive national surveys. The Lancet, Diabetes \& Endocrinology 7(4): P288-P299. 